\title{
On History in Formal Conceptualizations of Translation
}

\author{
Anthony Pym \\ Intercultural Studies Group \\ Universitat Rovira i Virgili \\ Tarragona, Spain
}

Version 1.3. April 2007

Text written following the conference Translation, the History of Political Thought, and the History of Concepts (Begriffsgeschichte), City University of New York, September 29th to October 1, 2005.

Any multilingual Begriffsgeschichte or histoire des idées requires some conceptualization of translation, no matter how minimal. If not, how are we to talk about the concepts (or Begriffe) or ideas (or idées) that come in different words? Some conceptualization of translation might reasonably be sought in the interdiscipline of Translation Studies, taken here as a mostly European set of discourses on the products and processes of translation. That discipline can indeed say something about translation, as we hope to show. Unfortunately, Translation Studies is not currently in any position to supply measures of comparison, or indeed any degree of surety about the distribution of concepts across languages and cultures. We cannot tell anyone that Begriff is the equivalent of idée, nor that it is a non-equivalent. The reason for this is quite simple. Since concepts of translation are themselves culturally variable, since there are shifts within their own translations, they cannot be used as a yardstick for relations between other concepts. Translation has its own Begriffsgeschichte, and possibly a histoire des idées as well. Yet how might those histories be written? No matter how frequently we fleetingly attribute equal values to terms like translation, traduction, Übersetzung and so on, the only guarantee of consistency is the assumption that they somehow translate each other, over time and across space. One would thus need some vague notion of translation before any such terms could be selected for analysis. Such a preliminary opening to the concept—what we are here terming a conceptualization-must somehow precede its historiography, even if only as a quickstep to set things in motion.

Translation Studies offers several ways of doing this. An inductive mode of conceptualization would set out from intuitively collected historical terms, related in 
terms of networks (cf. Akrich et al. 2006) or prototypes (cf. Halverson 2000). Such approaches can ultimately can be neither right nor wrong; perhaps all approaches have to start that way; the most damage they can cause is to suggest an ontology without epistemology. Other conceptualizations, however, are more explicit and formal in that they put forward deductive principles on the basis of which evidence will decide, however tentatively, what is or is not a translation. Those approaches are clear and conscious enough to be discussed in terms of right or wrong. They take risks and seek brevity, and there is thus much to say about them. Here we will briefly describe three such formalist attempts. We shall then test those proposals on the basis of several historical cases. The idea of an eternal concept of translation will be challenged, of course. Yet here we are more concerned with the historicity of the formalist project itself. If we are able to say anything at all about translation in the abstract, if we can indeed conceptualize it, does this mean that historicity immediately disappears from our object of knowledge? If not, at what stages, or by which routes, does historical variability emerge?

\section{Three formal conceptualizations}

Things were not so complicated for the linguistic paradigm that ruled in the 1960s or 1970s. Translation was then defined by equivalence, and the task of Translation Studies was to describe the modalities of that relation. Concepts could be traced across cultural boundaries in accordance with types of equivalence, which were held to be more or less constant. That general mode of thought was strongly marked by comparative stylistics (Vinay and Darbelnet 1958, Malblanc 1963). For example, “Défense de fumer” could be regarded as the functional equivalent of "No Smoking”, as indeed it still can be, no matter how different the syntactic structures may be. However, neat formulations of that kind were challenged by the analytical skepticism of Quine (1960), whose thesis of the indeterminacy of translation might allow for variants like "Smoking Prohibited", "Prohibition of Smoking”, “Do Not Smoke”, “Thank-you for not smoking”, and so on (possibly including the defective functionality of "Defense of smoking", which might work for some). Different translators can and do give different renditions; there is no one-to-one equivalence in the realm of natural languages. More significant for the history of political thought, the variation may be on the level of function as well as form. To take another throw-away example, “democracy” can mean radically different 
things in Pericles' Greece, Real Socialism and consumer capitalism, even despite apparent equivalence on the level of translingual morphology. For Quine, the different renditions "stand to each other in no plausible sort of equivalence relation however loose” (1960: 27). Equivalence will no longer help us decide what is right or wrong in translation. We can only observe the things that translators manage to get away with.

That position does not solve our problem. In order to demonstrate indeterminacy, any analysis has to enlist a series of potential translations, and Quine does not indicate how that might be done. More seriously, his reference to an "equivalence relation however loose" remains intellectually unsatisfying. The loosest definition could indeed hold that all translations are equivalent to each other simply by virtue of the fact that they are called translations. That is the position of the Israeli translation scholar Gideon Toury (1980: 63-70). We would then have to accept as equivalent the entire history of whatever translators have done with banalities like prohibiting smoking, or indeed with long-drawn aspirations such as democracy. Equivalence, with its implicit idealism of sameness or essential similarity, no longer has sufficient intellectual currency to start up our history.

For Gideon Toury, analysis should begin not from the fact that there are translations in the world (since they are all potentially equivalent to something, each in its own way), but from the assumption that such things exist. We should thus start by talking about “assumed translations". These, says Toury, may be identified in accordance with three postulates:

1. The source text postulate, which holds that "there is another text, in another culture/language, which has both chronological and logical priority over [the translation] and is presumed to have served as the departure point and basis for it” (1995: 33-34).

2. The transfer postulate: "the process whereby the assumed translation came into being involved the transference from the assumed source text of certain features that the two now share" (1995: 34).

3. The relationship postulate: "there are accountable relationships which tie [the assumed translation] to its assumed original” (1995: 35). It is presumably thanks to this postulate that we may talk about translations being more or less literal, function, adaptive, and so on. 
If these three postulates are held to be true, then we are dealing with an assumed translation, no matter what the local specific term for it may be. The formal conceptualization would thus hope to rise above the problem of how to translate the term "translation”. Problem solved?

Toury's three postulates would seem to delimit an eternal conceptual space for translation. Is there any history in that space, or is it only for angels? In practice, that space is remarkably broad. For example, it allows a corpus of translations to include "pseudotranslations", understood as target-culture texts presented as translations but which are in fact originals (an example would be Ossian, or perhaps Don Quijote, which declares itself to be a translation from Arabic). Toury has a certain penchant for the study of pseudotranslations, since they offer invaluable insight into what translations are expected to look like in different cultures. By allowing false translations to enter the conceptual frame, Toury would seem to move Translation Studies as far as possible from the idealisms of linguistic equivalence. To what might pseudotranslations be equivalent?

Note, also, that Toury's postulates are set up in such a way that translations can be analyzed within just one culture, the target (receptor) culture. In order to understand what translations are doing in that culture, there is no overriding need to compare them with any assumed originals. In this, Toury further reinforced his a radical break with the essentialism of equivalence-based studies. There is no question of Translation Studies attempting to judge to what extent all the features of an original have been transferred to a translation. Rather than compare the translation with its source, as was traditionally done, Toury would have us study the way translations operate within their culture. Translations can be compared with other translations, or with non-translations operative within the target culture. The timeless postulates thus further open to a rich and relativist historicity.

Are the three postulates successful? In their own terms, they are undoubtedly good enough for Toury's own historical studies to be set in motion, mostly on the roles played by translation in Jewish history. The conceptualization is nevertheless not without problems. The postulates are hardly elegant: one wonders if the third is really necessary (surely it is implicit in the other two?). The postulates are also willfully nonserviceable for disciplines that would seek precisely to compare concepts across languages (which is possibly one of the few things that any other discipline would ask of Translation Studies). Finally, they must be complemented by some consideration of 
exactly who is supposed to be doing all the assuming. To carry out historical research on assumed translations, we would have to locate subject positions for which the three postulates all hold. Someone in the target culture should actually believe these three things. Or is it enough for the analyst, the historian, to make the assumptions? If so, on the basis of what? Toury has remarkably little to say on the matter.

A second attempt at a formal conceptualization of translation is to be found in the work of the Ernst-August Gutt (1991), who is a linguist engaged in Bible translation projects (much of his work has been done in Ethiopia). Gutt sets out to apply linguistic relevance theory to translation, focusing on the cognitive processes by which linguist propositions are linked with contexts. Like Toury, he reduces equivalence to a general condition of all translations; he points out that every translation would logically need its own theory of equivalence. Unlike Toury, however, Gutt is clear about his focus on the receiving subjectivity as the key to his whole conceptualization of translation. He moves in two steps:

1. Translations can be either direct or covert. If they are direct, the receiver knows they are translations (the book says "translated by...” on the cover, for example). On the other hand, if a translation is covert, it might as well not be a translation (much advertising, for example, or indeed television news, is produced by translational processes but is not received as a translation). Gutt's interest is purely with the first kind, the direct translations.

2. A direct translation "creates a presumption of complete interpretative resemblance” (1991: 186). When a translation is received as a translation, the receiver thus presumes to understand what receivers of the original understood.

Gutt is very far from claiming there is any such thing as "complete interpretative resemblance” on the level of actual linguistic facts. Indeed, he sees texts as no more than sets of "communicative clues" that constantly require interpretation, and there is any number of ways in which those clues might be processed. The amazing thing is not that translations might sometimes lead to exactly the same interpretation (the possibility is by no means excluded - the Bible translator requires a certain idealism), but that receivers should believe that this can be the case at all. In a sense, translation boils down to a common discursive illusion, a convenient misconception encouraged by certain kinds of texts. 
Gutt's conceptualization has the virtue of elegance, and it is happily explicit in its placing of translation in the space of reception. To do history, we would have to locate series of instances in which receivers have believed in "complete interpretative resemblance" of one kind or another. Then again, what words would those readers have used for this thing? Surely not the words Gutt uses ("complete interpretative resemblance" does not really slip off the tongue). And what criteria would we then use to string together those different words in different languages? Surely we need to know something more about how to recognize this presumption?

Gutt's theory goes on to develop a preference for translations that show themselves to be translations, preferably those that make the reader work to find relations to source-culture contexts. That preference need not concern us here, except perhaps to the extent that it reposes on an ethics of honesty - better the text that shows itself to be what it is. And yet, what particular honesty can there be in any text that presents itself as a translation, when translations, on Gutt's account, are defined by a presumption that is easily misfounded? In the end, this is an elegant theory leading into a strange kind of ethics. And we shall leave it there.

A third attempt to conceptualize translation is in Pym (2004a), where the space of a translation is described in terms of two maxims:

1. The maxim of translational quantity holds that a translation represents an anterior text quantitatively. If a translation is longer, the anterior text is presumed to be longer as well.

2. The maxim of first-person displacement holds that the first person ("I") appearing in the translation is the same first person as the anterior text, even when the two texts are held to have been produced by different subjects. In other words, the person who says, "I am translating", as an instantaneous present, cannot be the translating translator.

These two propositions operate as maxims in the Gricean sense. When they are transgressed, specific meanings ("implicatures”) are produced and communicated. This is the way some discourses are able to parody or subvert dominant concepts of translation. In our own work, those threshold cases have assumed a certain political importance with respect to the historical roles played by translation (we shall see some examples below). Transgressions of the maxims would thus reveal the historicity of 
concepts of translation, in much the same way as pseudotranslations would provide information on culture-specific norms in Toury's approach.

We do not claim any superiority with respect to the previous conceptualizations. Our two maxims would hope to be broadly compatible with Toury's postulates or Gutt's conditions. Our initial purpose was perhaps slightly different: we sought to depend only on features that are available to textual analysis, thus avoiding the need to locate actual historical subjects as receivers. Markers of change in textual quantities (of explicit omission or addition) can be seen by all, as can pronominal structures. By simply looking at texts in these terms, we can see something of what those texts are saying about concepts of translation.

Of course, we do not entirely escape the problems incurred by Toury's or Gutt's approaches. Sooner or later we have to locate exactly who is making presumptions about text length, or for whom the pronominal positions are sufficiently distinct. In the end, translations are translations because someone accepts them as such, and our history has to locate the subject positions from which that acceptance is possible. However, we would hope to use textual analysis to guide us to those positions. Our maxims help us find situations in which the limits of translation are open to dispute, and that is where we find the subject positions. Rather than accumulate evidence of agreement or sameness, as if translation really were the same thing across all cultures, we prefer to start our history from arguments about what is or is not a (good) translation (cf. Pym 1998: 128). Such a way of collecting evidence is not only economical; it forces our initial conceptualization of translation to concretize into a series of concepts as we go along.

We have three broadly compatible formal conceptualizations. They go some way toward solving our problem. At the same time, these approaches are all from the same late-twentieth-century Western book culture. They are quite possibly from the one kind of culture that would seek to be as explicit as possible about texts as banal as translations, instinctively focusing on texts as products rather than speech as action, and presuming research methodology to be a problem in the first place. How could such a vision possibly speak to a history of all possible concepts of translation?

\section{Testing the limits of translation}


Here we seek to test the above approaches on a handful of historical examples. We are not particularly interested in the endless string of metaphors that have been used to describe translation (changing clothes, eating pre-chewed food, and so on). The metaphors tend to operate discourses on translations, sometimes in favor of them, more often against. That is quite different from saying what is or is not to be considered a translation. On the other hand, can we so easily overlook the actual terms used to refer to translations? The German compound Über-setzen could stir up images of something being taken over and set down, as opposed to the etymology of trans-lation, which might suggest a more simple movement across. Then again, etymology is no guide to usage, and the German and English terms could just as easily denote exactly the same concept. Can our conceptualizations overcome such doubts?

\section{Translation across time or space?}

One of the Sanskrit terms for translation is anuvad, which means, we are told, "saying after, saying again, repeating” (our thanks to Harish Trivedi for this example). If we try to conceptualize that term, the main difference between a translation and its source would be in time, not space. Translation might thus be seen as a process of drawing a text across chronology. Our current Western terms for translation, on the other hand, seem to privilege movement in a more physical spatial sense. So are we really talking about the same thing?

Even if interpreted in a radically non-European way, the semantics of anuvad would not seem to escape entirely from the net our three formal conceptualizations. With respect to Gutt, the term would indeed seem to denote a direct translation with “complete interpretative resemblance”. As for our own maxims, anuvad itself has little information that could seriously challenge expectations about textual quantities or pronominal structures. Nor does anuvad entirely bamboozle Toury's three postulates. There is certainly an anterior source, there is something in common between the translation and the source, and there is a patterned relationship between the two (in this case one of idealized sameness). One could nevertheless carp at Toury's use of the term "transfer" (his second postulate is the "transfer postulate"), which could introduce a spatial dimension not to be found in anuvad. To "say after" has quite a different directionality from "transfer" as a lateral movement from source to target. Or does it? What exactly does Toury mean by "transfer”? Try as we might, conceptualization 
processes cannot arise above the mesh of language, and at this particular point Toury's Western languages would certainly seem to be flavoring his thought.

One might be tempted to say that Toury, along with the entire discourse of "transfers", is thinking in a Western way, and that anuvad, with its non-reference to things moving from source to target, assumes a passivity that is entirely other.

That kind of opposition is to be resisted, for several reasons. First, there is a whole postmodern tradition in Western languages that would argue against this particular use of the term "transfer", so the problem cannot be the Western languages themselves. Second, for that matter, the Sanskrit term is itself presumably within some kind of Indo-European fold. Third, and more important, if we delve into the bases of Western tradition, we find ideas that would seem quite similar to anuvad, and with terms that are nevertheless compatible with Toury's use of "transfer”.

The medieval Christian tradition tended to conceptualize translation in terms of an idealized hierarchy of languages, with the tongues of revelation (Hebrew, Greek, sometimes Arabic) at the top, the language of science and authorized Biblical translation (Latin) on a next rung, then the vernaculars, and finally the patois. Translation was mostly seen as moving downward on this hierarchy, from a superior to an inferior language, thus requiring explanation and the development of new linguistic resources. The movement down the hierarchy was also a shift from older to newer languages, at least in terms of the medieval conception. This involved a sense of chronological rendition that we have largely lost in our contemporary preconceptions of lateral movements between equally developed languages. Within the hierarchy, the Romance terms for translation were mostly based on translat-, from translatus, past participle of the standard Latin verb transfero (to translate, to carry across, to transfer). The terms then underwent a major shift in the course of the fifteenth century. In the Hispanic tradition, the anthology of prefaces and theoretical comments compiled by Santoyo (1987) reveals the following development: transportament / translacio (1367), trasladar / traslado / trasladaçion (1415), trasladaçcion (1417), traslaçion (1428), traslaçion / trasladar / trasladador (c.1430), traduccion / traduzir (1438), translation (c.1440), traduçidor (1446), transportar / traslador (1450), traslados / traducion (1455). One then reaches a regime of new forms in traduc-, which underlies the current verbs traducción, traduire, tradurre, and so on.

As is well known, the forms in traduc- were largely instigated by Leonardo Bruni, who was using traduco and traductio in Latin from the beginning of the fifteenth 
century (Folena 1991: 71; Pym 2000: 108-131). Those terms were introduced to refer to a Humanist mode of translation focused on rhetoric, on the text as the expression of a coherent subjectivity. In passing, the new terms for translation presupposed that the languages involved were equally able to express style. They thus undermined the medieval hierarchy of languages, allowing for cross-cultural communication between subjects now on the same footing, as if the communication were across space (like a conversation) rather than across time (like a reverence to ancestors). The new terms have thus accompanied the centuries in which translation was idealized in terms of potential equivalence, albeit without that term.

This potted history hopefully reduces the apparent otherness of exotic terms for translation. The general sense of anuvad (Sanskrit also enjoyed a semi-divine status) is perhaps not entirely removed from the medieval bases of Western tradition. Modifications can certainly be made to the way we describe our conceptualizations. The entire vocabulary of "transfer" must indeed be questioned - meanings do not move. But we are not rooted to univocal languages, and historical research may thus nevertheless proceed.

The translation as what I would say

Our second case is more directly concerned with the problematic of subjectivity. Wace's twelfth-century Roman de Brut can be read as a translation of Geoffrey of Monmouth's Historia Regum Britannice, from which it takes most of its information about the legends of Britain. However, the text is not marked as a translation until the following lines occur, about half way through (Durling 1989: 9; cf. Pym 2004b) ${ }^{1}$ :

\begin{tabular}{ll}
\hline 1 & Dunc dist Merlin les prophecies \\
& Que vus avez, ço crei, oïes, \\
& Des reis ki a venir esteient, \\
& Ki la terre tenir deveient. \\
& Ne vuil sun livre translater \\
& Quant jo nel sai interpreter; \\
& Nule rien dire ne vuldreie \\
& Que si ne fust cum jo dirreie.
\end{tabular}

Durling translates the last line as "unless it were just as I should say", introducing a notion of external obligation and reducing the role of the first-person pronoun. Her final comments are nevertheless 
Then Merlin spoke the prophecies

Which you have, I believe, heard,

of the kings who were to come

and who should govern this land.

I do not want to translate [translater] his book

since I myself do not know how to interpret it.

I would not want to say anything

unless it were as I myself would say.

In refusing to translate at this particular point, Wace conveniently sidesteps the fact that Merlin was unlikely to have prophesized the Norman kings, who would certainly have been among Wace's receivers (his translation is in Anglo-Norman). The omission is politically astute. However, in making this remark the translator implicitly says, "I have been (and will be) translating”. The lines function as a kind of translator's preface, albeit placed near the middle rather than at the beginning of the text. Is the text then a translation?

For Toury’s three postulates, this example presents no particular problem, none the least because the verb translater is closer to transfer than to most of our contemporary terms for translation (the movement is indeed downward, from Latin to the Anglo-Norman vernacular). Further, Wace's text presents a very clear and specific "accountable relation", since here the translator implicitly declares himself to be personally accountable for everything that he does choose to render. That is not generally a responsibility we ask translators to take on in our own day. However, it poses no particular problem for Toury’s postulates.

How does Gutt's “complete interpretative resemblance” fare here? This is more difficult. In stating that he only renders texts that are in accordance with his own disposition, Wace allows that he has omitted other passages, not only Merlin's speech. On this understanding, the presumed interpretative resemblance might be considered complete (in a highly ethical sense) between the translation and its corresponding source-text passages, but not between the translation and its source as a whole. With this proviso, the presumption of complete resemblance should nevertheless hold.

judicious: "For Wace, translation is a vision of truth which allows the author to add or delete material. It implies interpretation based on the author's own erudition, is suggestively linked to paternity, and is not discussed as a product of patronage” (1989: 30). 
Our own maxims are more seriously in trouble here. The maxim of quantitative congruence is clearly broken, since the translation is marked as being significantly shorter at this point. Yet the transgression is motivated and meaningful, underscoring the mediator's shared responsibility for the translational discourse. The breaking of the maxim itself need not lead to any kind of non-translation for the rest of the text. As for the maxim of first-person displacement, the eruption of the translator's voice in the midst of the translation is a highly unusual transgression, but it does make sense. By definition, the part of the text where Wace speaks in the first person is not translational; it is a meta-translational discourse, and little more than that. Again, the fact that the translator implicitly takes responsibility for the words translated is unusual, but not unaccountable.

The translation as what I cannot say

In 1526 Alonso Fernández de Madrid finished his Spanish version of Erasmus’s Enchoridion. Even the most cursory inspection will show that this translation is much longer than its original, to an extent that cannot be explained away by quibbles about how one assesses length. Should this obvious expansion create doubts about the translational status of the text? The translator's preface to the work (cf. Santoyo 1987: 49-52) touches all the bases for a translation of its day, finding inspiration in classical fidelity, with references to Saint Jerome and the like. On the basis of the preface, the text does indeed invite assumptions of "complete interpretative resemblance”; it does little to upset any of Toury’s postulates (at least not until we actually look for patterned relationships); it satisfies our concerns about pronominal structures, and it might even elude the maxim of quantity, albeit only for as long as no historical reader was likely to put the source and the translation side-by-side. Unfortunately, one institutional reader was quite likely to do just that. That reader was called the Holy Office, the Inquisition. Institutional attacks on Erasmus had been going on since 1520.

Fernández de Madrid’s work looks like a translation and is indeed a translation, in part. The text also adds much material to Erasmus, and omits quite a deal too. The preface, with its claims to fidelity, is a sham (as a general rule, translators' prefaces hide more than they reveal). Without pursuing the details, let us propose that Fernández de Madrid uses the veneer of translation in order to give his own account of nonconformist ideas, preaching through the foreign persona of Erasmus. Why should he do 
that? Presumably, it was in order to deny complete responsibility in the case of public dispute. The translator would only be the messenger; the author, distanced, would be the one fully responsible. In this, the expansive translator would rejoin the authors of pseudotranslations (all those translations for which there has never been any original). Whereas Wace only rendered those ideas he was politically able to take responsibility for, Fernández de Madrid might well have chosen the translational form in order to express precisely those ideas for which he was not prepared to take full responsibility.

Both strategies are possible within the space mapped out by our conceptualizations of translation. Their history can be fought out within our project.

\section{Conclusions, mainly for historians of political thought}

Our prime purpose has been to demonstrate that the use of formal conceptualization can allow for considerable variation, and thus historicity. To talk about limits to the space of translation need not preclude many wonderful and varied things from happening on and across those limits.

We would also hope to say something to historians of political thought. The conference in New York in October 2005 demonstrated the extensive and complex body of knowledge that translations retain concerning the way ideas disseminate. From the perspective of Translation Studies, many of the papers presented fascinating insights able to enrich our theories and histories of translation. However, one of the main risks for any cross-disciplinarily on this level must be the frequent assumption that translation is simply what it has always been. Translation is what it has always been, but not simply so. When historians talk about translation, there are certain aspects that we translation scholars would like to know much more about.

For example, translation concerns texts, not concepts, and those texts must be interpreted in quite specific terms. To see how a concept of translation is operating in any particular circumstance, we need information on the expectations that are created, the quantities involved, and the subject positions occupied. All that is the affair of considerable stretches of discourse.

Similarly, for the formal approaches we have brought together here, the status of a text as a translation is determined in the receptive situation. The historical study of translations must thus seek the receivers for which the translation could be accepted as 
such. Discursive analysis can take us part of the way there. Empirical histories, however, should be able to turn the subject positions into people.

Further, a history of texts and text receivers would hopefully be able to say something about that most hidden of subject positions, the translator. In principle, translators cannot say "I" within the text of a translation. In practice, their discursive invisibility is fairly easily outlined, allowing for a range of positions with regard to what is said in the translation. Translators can ally themselves with an author, hide behind an author, distance a text, obscure thought, adapt ideas to new receivers, and much else besides. How and why they do this is heavy with consequence for the ways translations have long evaded ideological censors.

Our formal conceptualizations would thus allow considerable space for the historical study of textuality, receptive positions, and the semi-concealed subjectivities of translators. That is from our own agenda, from within Translation Studies. It need not be anyone else's agenda. But if historians can tell us more about those aspects, we promise to listen and take note. Our formal conceptualizations are by no means closed.

\section{References}

Akrich, Madelaine, Michel Callon, Bruno Latour (2006) Sociologie de la traduction. Textes fondateurs. Paris: Presses de l’École des Mines.

Durling, Nancy Vine (1989) “Translation and Innovation in the Roman de Brut”. In Jeanette Beer (ed.) Medieval Translators and their Craft. Kalamazoo, Michigan: Medieval Institute Publications, Western Michigan University.

Folena, Gianfranco (1991) Volgarizzare e tradurre. Torino: Einaudi.

Halverson, Sandra (2000) “Prototype effects in the 'translation' category”. In Translation in Context. Andrew Chesterman, Natividad Gallardo San Salvador and Yves Gambier (eds). Amsterdam and Philadelphia: John Benjamins. 3-16.

Gutt, Ernst-August (1991) Translation and Relevance. Cognition and Context. Oxford: Basil Blackwell.

Malblanc, André. (1963) Stylistique comparée du français et de l'allemand: Essai de représentation linguistique comparée et étude de traduction. Paris: Dider.

Pym, Anthony (2000) Negotiating the Frontier: Translators and Intercultures in Hispanic History. Manchester: St Jerome Publishing. 
Pym, Anthony (2004a) "Propositions on Cross-Cultural Communication and Translation”, Target 16(1). 1-28.

Pym, Anthony (2004b) The Moving Text. Translation, Localization, and Distribution. Amsterdam and Philaelphia: John Benjamins.

Quine, Willard Van Orman (1960) “Translation and Meaning”, chapter of Word and Object, Cambridge MA: MIT Press, 26-79.

Santoyo, Julio-César (1987) Teoría y crítica de la traducción: Antología. Bellaterra: Universitat Autònoma de Barcelona.

Toury, Gideon (1980) In Search of a Theory of Translation. Tel Aviv: Porter Institute for Poetics and Semiotics.

Toury, Gideon (1995) Descriptive Translation Studies and beyond. Amsterdam \& Philadelphia: Benjamins.

Vinay, Jean-Paul \& Jean Darbelnet (1958) Stylistique comparée du français et de l'anglais: méthode de traduction. Paris: Didier. 